DOI: $10.1515 /$ rpp-2017-0020

$\mathrm{PhD}$ in Pedagogical Sciences, Associate Professor, LIUDMYLA MILTO Institute of Pedagogical and Adult Education of the National Academy of Pedagogical Sciences of Ukraine Address: 9 Berlynskyi St., Kyiv, 04060, Ukraine E-mail: miltolo@ukr.net

\title{
HISTORIOGRAPHIC ASPECTS OF STUDYING THE PHENOMENON OF PEDAGOGICAL MASTERY (ANALYSIS OF UKRAINIAN AND FOREIGN SCHOLARS' VIEWS)
}

\begin{abstract}
The article is devoted to scientific analysis of the phenomenon of pedagogical mastery. Research findings on pedagogical mastery, pedagogical creativity, pedagogical technologies have been studied in the light of historical and pedagogical paradigm. In addition, various scientific approaches and views of scholars on the essence of pedagogical mastery have been considered and the ambiguity of their scientific interpretations has been justified. The scientific category of pedagogical mastery is regarded as a social, cultural and historical phenomenon, caused by the challenges of society in line with the relevant social priorities and directions according to the goals and objectives of a particular historical period. Subsequently, complexity and multidimensionality of the notion of pedagogical mastery and presence of various scientific approaches (technological, creative, personality- and activitybased) to interpreting the scientific category have been proved. Based on the current sociocultural situation, the relevance of researches on pedagogical mastery as a scientific category has been proved and its role in training future teachers, which can be considered as a certain teaching strategy and factor in forming their readiness for innovative activity has been defined. It has been found out that diversity and interdisciplinarity of pedagogical mastery in the system of scientific knowledge promote methodological strategies for its research, the need for their systematization and complex implementation.

Keywords: pedagogical mastery, professional training, pedagogical art, pedagogical technology, pedagogical technique, pedagogical creativity, innovation technologies.

\section{INTRODUCTION}

Ukraine's joining the Bologna Process requires reforming the education system as well as updating its content and structure. Consequently, entering the European Educational Space should positively affect the quality of pedagogical training, raise competitiveness of higher education harmonization. A balanced and systematic increasing the level of qualifications of teaching staff is currently the main problem of social development in the context of higher education europeanization and one of the most important tasks in education.

Foreign and native experience shows that positive changes in education will not take place unless the level of teachers' professionalism increases. At all stages of the historical development of education, the problem of pedagogical mastery was and is the most urgent one, since productivity of education and training and professional training of teaching staff are directly dependent on the willingness of teachers to perform their professional duties. The quality of education has always been determined by a national priority of the state, so studying the phenomenon of pedagogical mastery with the aim to
\end{abstract}


enhance professional training of teachers has been the subject of researches by many scholars, educators, psychologists, philosophers, sociologists, teachers-practitioners.

\section{THE AIM OF THE STUDY}

The aim of the study is to specify the categorial status of pedagogical mastery and outline various scientific views and approaches to understanding the phenomenon of pedagogical mastery.

\section{THEORETICAL FRAMEWORK AND RESEARCH METHODS}

At the modern stage, development of pedagogical mastery is based on psychology of creativity, pedagogical acmeology, pedagogical culture, pedagogical ethics, pedagogical creativity and pedagogical technology.

While researching we have attempted to take into consideration all the abovementioned aspects of the problem under study. Therefore, we have appealled to many researches by Ukrainian and foreign scholars. It must be noted that there are numerous works on the matter, although we have chosen, in our opinion, the most relevant ones. Thus, we considered the essence of pedagogical mastery beginning from the early 20th century. We believed it necessary to study the interpretations of pedagogical technology, pedagogical creativity and pedagogical mastery in the retrospective of their forming based on the views of Ukrainian (A. Makarenko, M. Potashnik, A. Sbruieva, I. Ziaziun), American (B. Bloom, D. Bruner, J. Caroll, A. Maslow, K. Rogers), Russian (A. Bekhterev, V. Pavlov, S. Shatskiy, A. Ukhtomskiy), German (H. Grassel, J. Habermas, J. Herbart) scholars. We concluded that these views may have different background, yet they agree on the point that pedagogical mastery is a complex process based on two important "pillars", namely, pedagogical technology and pedagogical creativity that are closely interrelated.

To obtain objective historical data on the problem under study, we used a set of theoretically interrelated methods of a historical and pedagogical research, namely, general scientific (historical and pedagogical analysis, synthesis, generalization, comparison); specific search methods (terminology analysis, systematization of foreign and nativeresearch findings).

\section{RESULTS}

A scientific analysis and synthesis of historical experience suggests that pedagogical mastery of the teacher was the subject of philosophical studies as far as back in ancient times, and the term "art of education" was defined as a set of professional traits that help the teacher successfully direct the education process. The ancient Greeks, the Sophists (teachers of wisdom, masters) used the term "hevrestes" (skilled, experienced, competent) to characterize people who achieved great results and regarded human as an individual. The ideas of pedagogical mastery were filled with the new content and underwent qualitative changes during the Enlightenment in the works of J. A. Comenius, J. Locke, J.-J. Rousseau et al.

Scientific and technological progress of the 20th century has caused technologization of not only many industries but also culture, pedagogy, humanities. Of particular interest in pedagogical science and practice during this period are studies on the relationships between pedagogical mastery and pedagogical technology as its component that are closely related to each other. This is not a coincidence that the Greek word "techno" means art, mastery, skillsthe craftsman needs to make things under the guidance of the mentor due to his diligence and motivation. The term "technology" includes not only the art of mastering the very process, but also its standardization and unification, the opportunity of its implementing under given conditions.

It must be noted that the term "pedagogical technology" was first used in pedology in the 1920's in the papers on reflexology by such Russian researchers as A. Bekhterev, 
V. Pavlov, S. Shatskiy, A. Ukhtomskiy, where this concept was related to pedagogical technique. Pedagogical technology also involved the ability to use educational and laboratory equipment as well as visual methods. In the 1930s, the term "pedagogical technique" was mentioned in Pedagogical Encyclopedia and defined a set of means aimed at clear and effective organization of lessons.

In the 1920s, the former Soviet Union launched the education reform accompanied by introduction of innovative principles into organization of the education process. A. Makarenko (1954), believing that education should be organized as mass production, pointed out that while "constructing" personality one should take into account individuality, integrity, originality of the talent, interests and inclinations. The teacher-innovator was first to distinguish pedagogical technique as a part of pedagogical mastery, emphasizing the need for special professional upbringing.

A massive introduction of pedagogical technologies took place in the early 1960s, which was associated with reforming schools in the USA and Western Europe. The term underwent a number of changes, namely, from "technology in education", "educational technology" to "pedagogical technology". American scholars B. Bloom (1956), D. Bruner (1966), J. Caroll (1963), et al. associated technology of the education process with the concept of its optimization and development of appropriate techniques. According to T. Matsuda \& T. Sakamoto (1991), pedagogical technology means implementation of systemic thinking into pedagogy that is identified as "systematization of education".

B. Bloom (1956) published a framework for categorizing educational goals: Taxonomy of Educational Objectives. Familiarly known as Bloom's Taxonomy, this framework has been applied by generations of teachers and college instructors in their teaching. The framework consisted of six major categories: Knowledge, Comprehension, Application, Analysis, Synthesis and Evaluation. The categories after Knowledge were presented as skills and abilities, with the understanding that knowledge was the necessary precondition for putting these skills and abilities into practice. While each category contained subcategories, all lying along a continuum from simple to complex and concrete to abstract, the taxonomy is popularly remembered according to the six main categories.

Here are the authors' brief explanations of these main categories in from the appendix of Taxonomy of Educational Objectives: Knowledge "involves the recall of specifics and universals, the recall of methods and processes, or the recall of a pattern, structure, or setting; comprehension "refers to a type of understanding or apprehension such that the individual knows what is being communicated and can make use of the material or idea being communicated without necessarily relating it to other material or seeing its fullest implications; application refers to the "use of abstractions in particular and concrete situations; analysis represents the "breakdown of a communication into its constituent elements or parts such that the relative hierarchy of ideas is made clear and/or the relations between ideas expressed are made explicit; synthesis involves the "putting together of elements and parts so as to form a whole; evaluation engenders "judgments about the value of material and methods for given purposes (Bloom, 1956).

Based on the mentioned above, we can conclude that 1) objectives (learning goals) are important to establish in a pedagogical interchange so that teachers and students alike understand the purpose of that interchange; 2) teachers can benefit from using frameworks to organize objectives because 3) organizing objectives helps to clarify objectives for themselves and for students; 4) having an organized set of objectives helps teachers to plan and deliver appropriate instruction; design valid assessment tasks and strategies; ensure that 
instruction and assessment are aligned with the objectives. So, B. Bloom's Taxonomy can and should be applied in practice by any teacher who wants to achieve pedagogical mastery through a well-elaborated framework of educational objectives that exactly define what pedagogical techonologies are advisable.

One may start with the very diffrent assumption that individual students may need very different types of educational technologies. J. Caroll (1963) defines the quality of teaching in terms of the degree to which the presentation, explanation and ordering of elements of the task to be learned approach the optimum for a given learner.

J. Bruner (1966) believes that teaching is a provisional state that has as its object to make the learner of problem-solver self-sufficient based on educational technologies. The teacher must correct the learner in a fashion that eventually makes it possible for the learner to take over the corrective function themselves. Otherwise the result of teaching is to create a form of mastery that is contingent upon the perpetual presence of the teacher.

To justify development of the views on the concept of pedagogical technology in Germany, it is important to mention valuable ideas of J. Herbart. Thus, the educator who takes up the duties should have a certain map or plan: "What is important for the teacher should be shown to them as a map (if possible) or a plan of the well-built city, where similar trends clearly overlap and where they can orientate on their own". Of particular interest is an opinion regarding creation of a technological map of the education process characterized by a sequence of actions, simultaneously paying tribute to pedagogical mastery. In addition, to understand the process of pedagogical technology development, one should consider J. Herbart's justification of the need for taking into account the impact of psychological theories on the education process (Somr \& Hrušková, 2014).

In addition, in J. Herbart's own words, teaching is the "central activity of education". His own thinking, personal experience and experimentation convinced him of the astonishing effects of educational teaching: the individual who acquires a "versatile range of interests" through teaching will "be capable" of doing with inner ease everything that he "wishes" to do after "mature reflection". He will always keep his ethical ideal clearly in mind and, in his progress towards the attainment of that ideal, he will be able to rely on his own pleasure in further learning and on the dependable "strength of his own character" (UNESCO: International Bureau of Education, 1993).

In the Glossary of educational technology terms prepared by the Division of Educational Sciences, Contents and Methods of Education, UNESCO for the International Bureau of Education in 1986, it is stated that pedagogical technology originally means the use of educational means (audio, video, computers, etc.) In the new and broad sense, it is a systematic method of planning, application and evaluation of the entire education process, mastery of knowledge and skills by taking into account human and technological resources and the interaction between them to achieve an effective form of education. In this regard, pedagogical technology is used as a theoretical tool of systemic analysis (UNESCO, 1986).

It must be noted that the founder of pedagogical mastery I. Ziaziun indicated that the state and development of education systems in every era can be measured in terms of pedagogical technologies. The scholar believed that tracing dynamics of such phenomena as individual mastery (the teacher's creativity) and use of established active methods and forms of education, one can determine that development of learning tools and methodologies related to them, increase in their significance within the education systems from age to age stimulated the process of pedagogy technologization. According to I. Ziaziun (2003), "pedagogical technology includes methods, learning tools as well as theory and practice 
of their use to achieve the goals of education and may involve other various specialized technologies, common in other areas of science and practice: new information technologies, industrial, electronic, printing, medical ones, etc." (p. 224).

A. Sbruieva (2004), who studied the education systems of developed Englishspeaking countries, described the system of teachers' professional development in the USA and pointed out the positive impact of technological approach to improving their professional skills. The scholar indicated, "an important role in development of teachers' online collaboration is played by electronic conferences that allow to discuss educational materials, students' attainment, quality of standards, test programs, etc. The participants of such conferences can be as teachers from neighbouring classes as experts from the other side of the world" (p. 85).

While forming pedagogical mastery of teachers in the system of higher education of Canada, they use different strategies, traditional and those that are not common for professional training of specialists in Ukraine. The most common technologies are considered to be direct and indirect learning technologies. Direct technology is based on the teacher and proves to be effective while providing information or developing skills. Direct technology includes different methods (lectures, mini-lectures, practical classes, demonstration, tests, quizzes, etc.). Indirect technology is aimed at student personality that distinguishes it from the direct one. However, both technologies may complement each other. The examples of indirect technologies are reflective discussion, concept forming, unconventional problem solving, intellectual maps, the case method, etc. This technology allows future pedagogues to develop their creative and communication skills. Yet, it still has certain drawbacks: it is more time-consuming than direct technology and does not cover all the aspects of information transmission (Tamburri, 2011).

Interesting methodological approaches to studying efficiency of teachers' pedagogical activity were suggested by Prof. H. Grassel (1968) from the University of Rostock. He conducted researches on professional activity of the teacher-master. Thus, the scholar applied the following methods: 1) studying the degrees of the teacher's influence on student body through surveys and questionnaires; 2) motivating the teacher toward professional efficiency with the help of the very teacher (self-esteem), their colleagues, school administration, students' parents; 3) evaluating the teacher's personality with the help of their students, school-leavers, colleagues, school administration, students' parents, the very teacher (self-esteem); 4) observing the teacher's professional performance within educational situations, curricular and extracurricular activities; 5) studying the teacher's arbitrary behaviour: self-esteem, peer review, school administration review, parents and students review; 6) analyzing the documentations that records the teacher's activities (lesson planning).

We believe it necessary to indicate that experience of foreign countries assumed the main category of pedagogy of cooperation to be communication. This greatly contributed to justification of the teacher's professional qualities. J. Habermas (1984) stated that the main task of the teacher is to transform immaturity into professional integrity that may be achieved through self-regulated study in the context of communication, activity and cooperation. These are the main types of activity the teacher should be ready for.

Research findings prove that modernization processes took place in the United States of America, too. It must be noted that during the early 1970s in the USA one observed the emergence of a new direction called "pedagogical education based on pedagogical mastery" aimed at characterizing the teacher-master, formulating the 
requirements to their professional knowledge and skills. In American pedagogical literature, the concept of pedagogical mastery is defined by several terms, namely, "skillful teaching", "effective teaching", "art of teaching", "teaching based on excellence", "competent teaching" (Melish, 2016).

It is well-known that pedagogical creativity is an essential condition for development of the teacher's professional skills, which can be described as the search for new, innovative ways to solve educational problems; original, optimal and rational methods of creative interaction between the teacher and the student and their realization in professional activity.

Considering the categorical relationship between pedagogical creativity and pedagogical mastery, M. Potashnik (1988) indicated that the master is a person who has mastered their profession. The scholar pointed out that a creative teacher may not have time to become the master, but they manage to reach a higher level of mastery only through creativity, diligence, perseverance, efficiency, overcoming difficulties, transforming abilities into skills and, finally, gaining experience. Thus, the teacher should first develop their creativity skills and only then - pedagogical mastery.

According to humanistic theory of the American psychologist A. Maslow, creativity is a universal function of personality that is inherent in every human being. The scholar believed that as a result of "cultivation" many people lose this quality, when personality is able to renew it by constant communicating with those who are eager to create. Individuals need "favourable" environment where they can reveal their potential to the full. K. Rogers, who shared A. Maslow's views, believed that the main motive of human life is self-actualization as one of the most important sources of vital power. It facilitates a maximal manifestation of personality abilities with the aim of self-preservation and self-development (Sincero, 2012).

It must be noted that the relationship between creativity and critical thinking is close, almost symbiotic in as much as creativity needs the ground that is prepared by critical thinking in which to grow. One of the principle outcomes, therefore, of creative teaching is a growing facility in learners to make appropriate and informed critical judgements that will be seen as well-grounded evaluations of relative worth as applied to their decisions, their actions and all the elements of the sea of stimuli in which they exist. It is seen by some researchers as being one of the essential skills needed to participate effectively in today's society (ten Dam \& Volman, 2004).

\section{CONCLUSIONS}

Historiographical aspects of the study on the phenomenon of pedagogical mastery indicate the evolution of terminological definitions according to historical stages of the global society associated with the radical changes taking place in social, economic, political, cultural life of the country as well as values, priorities and information and communication technologies.

A retrospective analysis of development of the views on pedagogical mastery has allowed to define the presence of various scientific approaches (technological, creative, task-, personality- and activity-based) to understanding the concept of pedagogical mastery. It has been found out that pedagogical mastery is defined by a high level of comprehending pedagogical technology and includes the teacher's readiness for innovations by creating a system of continuing creative professional development. Fundamentality, consistency, scalability, autonomy of pedagogical mastery, its interconnection with the concepts that 
characterize high-quality, productive pedagogical work: pedagogical professionalism, pedagogical creativity, pedagogical culture, pedagogical technologies and pedagogical innovations.

This proves the need for further comparative studies on the innovative system of teachers' professional training in national and international practice and the use of positive aspects of foreign experience in training teachers.

\section{REFERENCES}

1. Bloom, B. S. (1956). Taxonomy of educational objectives. Boston, MA: Allyn and Bacon.

2. Bruner, J. (1966). Toward a theory of instruction. Cambridge, MA: Harvard University Press.

3. Caroll, J. (1963). A model of school learning. Teachers college record, 64, 723-733.

4. ten Dam, G. T. M., \& Volman, M. L. L. (2004). Critical thinking as a citizenship competence: teaching strategies. Learning and instruction, 14 (4), 359-379. DOI: 10.1016/j.learninstruc.2004.01.005.

5. Grassel, H. (1968). Probleme und Ergebnisse von Untersuchungen der Lehrertätigkeit. Rostock: Studie des Wissenchaftsbereichs Pädagogische Psychologie der Universität Rostock.

6. Habermas, J. (1984). The theory of communicative action, London: Beacon Press.

7. Makarenko, A. S. (1954). Tvory $v 7$. Kyiv: Radianska shkola.

8. Matsuda, T., \& Sakamoto, T. (1991). Development and evaluation of a curriculum for informatics education by means of logo programming at higher grades of elementary schools. Japan journal of educational technology, 15 (1), 1-14.

9. Melish, J. P. (2016). Public history and American studies pedagogy. American quarterly, 68 (2), 367-370.

10. Potashnik, M. M. (1988). Pedagogicheskoe tvorchestvo: problemy razvitiia $i$ opyt: posobie dlia uchitelia. Kiev: Radianska shkola.

11. Sbruieva, A. A. (2004). Tendentsii reformuvannia serednoi osvity rozvynenykh anhlomovnykh krain v konteksti hlobalizatsii (90-ti rr. XX-pochatok XXI st.). Sumy: VAT "Sumska oblasna drukarnia"; Vydavnytstvo "Kozatskyi val".

12. Sincero, S. (2012). Humanistic perspective and personality. Retrieved from https://explorable.com/humanistic-perspective-and-personality.

13. Somr, M., \& Hrušková, L. (2014). Herbart's philosophy of pedagogy and educational teaching. Studia edukacyjne, 33, 413-429.

14. Tamburri, R. (2011). Canadian-style pedagogy takes roots overseas. Retrieved from http://www.universityaffairs.ca/features/feature-article/canadian-stylepedagogy-takes-roots-overseas/.

15. UNESCO. (1986). Glossary of educational technology terms. Retrieved from http://unesdoc.unesco.org/images/0007/000718/071833mo.pdf.

16. UNESCO: International Bereau of Education. (1993). Johann Friedrich Herbart. Prospects: the quarterly review of comparative education, XXIII (3/4), 649-664.

17.Ziaziun, I. A. (2003). Osvitni paradyhmy v konteksti filosofskykh idei. In T. Levovytskyi, I. Vilsh, I. Ziaziun, N. Nychkalo (Red.), Profesiina osvita: pedahohika $i$ psykholohiia: Polsko-ukrainskyozhurnal (S. 221-222). Częstochowa-Kyiv: Vydavnytstvo Vyshchoi pedahohichnoi shkoly u Chekhonstovi. 